\title{
Sublingual Schwannoma: A Rare Clinical Entity reported in a Hypothyroid Female
}

\author{
Sudhir M Naik, MK Goutham, S Ravishankara, Mohan K Appaji
}

\begin{abstract}
Background: Schwannomas are solitary, encapsulated tumor usually attached to, or surrounded by a nerve and are not associated with von Recklinghausen's disease and rarely show malignant degeneration.
\end{abstract}

Setting: Department of ENT, Head and Neck Surgery, KVG Medical College, Sullia.

Case report: A 68-year-old female presented with pain at the left side of the tongue since 1 month. Also a firm to soft $7 \times 5 \mathrm{~cm}$ sublingual swelling of long-standing duration was seen. FNAC was inconclusive and contrast CT showed a sublingual swelling with mild-contrast enhancement.

Intervention: Sublingual excision of the tumor was done under general anesthesia and the tumor enucleated. No complications were seen and the recovery was uneventful. Histopathological report came as benign schwannoma and immunoreactive to S100 protein.

Conclusion: Most of the intraoral schwannomas are managed by complete surgical excision and recurrence are not reported. Malignant transformation is not seen in any of the intraoral schwannomas but definite preoperative diagnosis is necessary to avoid wide excision when the tumors can be easily enucleated without recurrence.

Keywords: Schwannoma, Sublingual region, Enucleation, Contrast CT scan.

How to cite this article: Naik SM, Goutham MK, Ravishankara S, Appaji MK. Sublingual Schwannoma: A Rare Clinical Entity reported in a Hypothyroid Female. Int J Head and Neck Surg 2012;3(1):33-39.

\section{Source of support: Nil}

Conflict of interest: None declared

\section{INTRODUCTION}

Schwannoma is a benign neural tumor of ectodermal origin derived from spindle-shaped Schwann cells or nerve fiber sheath cells. ${ }^{1}$ They are also called neuromas or neurilemmomas. ${ }^{2}$ They are common slow growing, solitary and wellencapsulated tumors derived from Schwann cells located at the sheaths of peripheral, cranial or autonomic nerves. ${ }^{3}$

They are a solitary, encapsulated tumor usually attached to, or surrounded by a nerve, and are not associated with von Recklinghausen's disease and rarely show malignant degeneration. ${ }^{3,4}$ Neurites are not a component of the tumor as in the case of neurofibroma or other neural (benign) tumors. ${ }^{3}$ Schwannomas may arise anywhere in the body, but they have an affinity for the head and neck region and extremeties. ${ }^{5}$

Around 25 to $48 \%$ of schwannomas are seen in the head and neck region and most of them occur in the intracranial region and rarely observed in the extracranial region and that too extremely rare in the floor of the mouth. ${ }^{1,3}$ Around 20 to $58 \%$ of head and neck schwannomas arise in the oral cavity and schwannomas of peripheral position of the cranial nerve usually affect soft tissues of the head and neck. ${ }^{6,7}$ Only $1 \%$ of the schwannomas are seen intraorally. ${ }^{3}$ Tongue is the most commonest site of schwannoma. ${ }^{3}$

These benign tumors occur regardless of age or sex and are painless, insidious and slow growing. ${ }^{2,8}$ So, they are of long duration at the time of presentation and rarely show a rapid course. ${ }^{3}$ In the head and neck, schwannomas usually arise from the sensory divisions of cranial nerves, most commonly the vestibular nerve and the vagal nerve. ${ }^{1}$ Around 10 to $40 \%$ of extracranial schwannomas were not identified with the nerve origin. ${ }^{9-11}$ They are usually reported in the 3rd to 4th decade but cases in the first year of life are also reported. ${ }^{12-14}$ We report a case of schwannoma of sublingual region wherein the nerve of origin was not identified.

\section{CASE REPORT}

A 68-year-old female presented with pain at the left side of the tongue since 1 month (Figs $1 \mathrm{~A}$ and $\mathrm{B}$ ). She was examined at our department of ENT, head and neck surgery and an ulcer was found at the left border of the tongue. Also was seen a mass on the sublingual aspect pushing the tongue to the right. The mass was pushing the tongue dorsally and was palpable as a soft cystic to firm in consistency on palpation. The ulcer was $1 \times 1 \mathrm{~cm}$ in size, which was caused probably because of the mass pushing it laterally against the sharp teeth. A biopsy of the ulcer was taken and mild dysplastic changes were seen (Figs 2A and $\mathrm{B})$.

Palpation of the intraoral mass bidigitally revealed a soft, painless, well-defined without any evidence of atrophy or paralysis of the left half of the tongue. The excision biopsy of the ulcer was taken and the sharp spike of the teeth was resurfaced. Contrast CT scan with nonionic iohexol with tromethamine contrast medium was done along with fine 

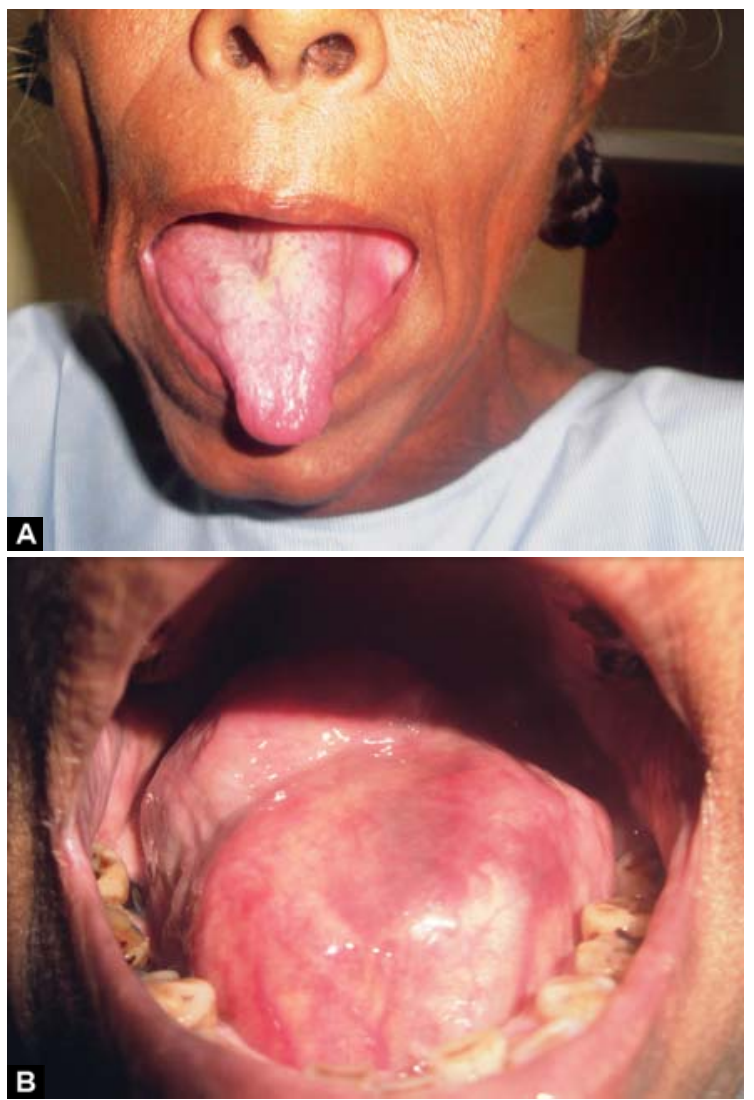

Figs $1 \mathrm{~A}$ and B: Sublingual swelling pushing the tongue to the right
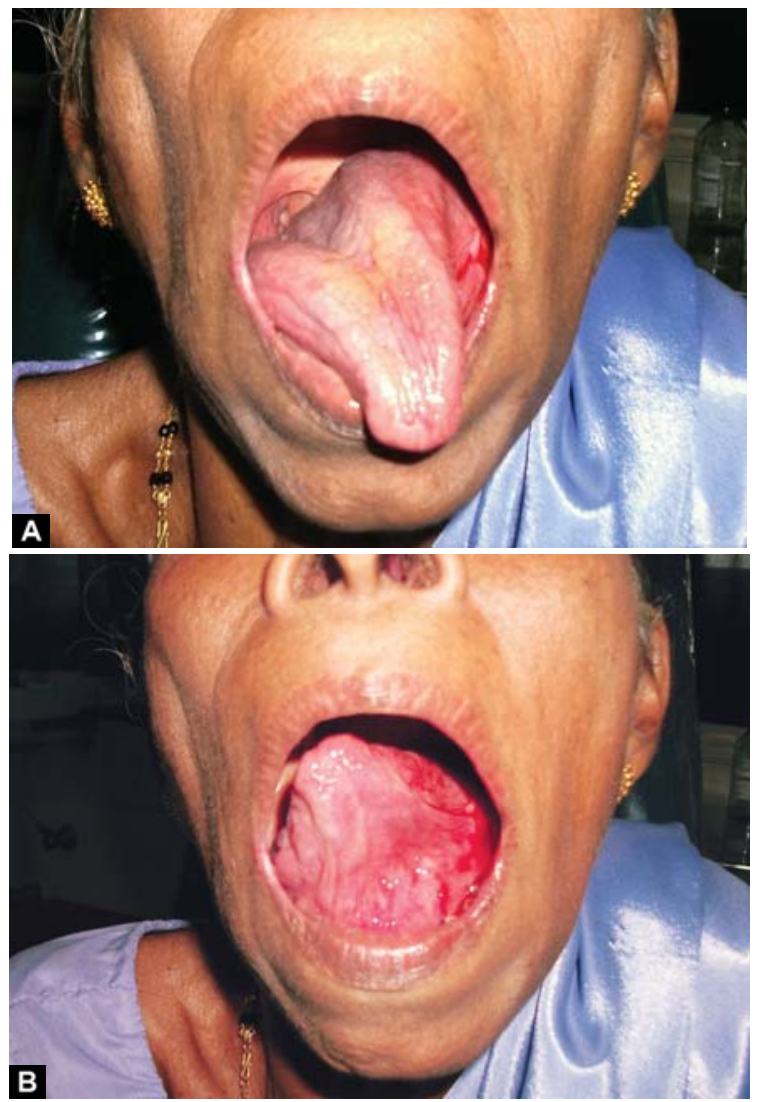

Figs 2A and B: Biopsy taken from the left lateral aspect of the tongue from the ulcer needle aspiration cytology (FNAC) (Figs 3 to 6 ). The FNAC was inconclusive and a differential diagnosis of lipoma was thought of. The mass did not take up much enhancement on contrast CT, so a diagnosis of a tumor of the size of $7 \times 5 \mathrm{~cm}$ was lying below the muscles of the tongue and well encapsulated was made. She was hypothyroid and was on thyroid supplementation for the past 18 years and the current thyroid profile showed euthyroid status. All other investigations were under normal limits and the patient was taken as ASA grade II for elective surgery.

Sublingual excision of the tumor was done under general anesthesia and the tumor enucleated by dissecting the flimsy adhesions keeping in mind to avoid any nerve entering it. The tumor was removed by displacing the mylohyoid downward and the bulk of the longitudinal muscles laterally and as the tumor popped out, small vessels entering it were separated from it and cauterized. The ulcer over the mucous membrane was excised with a $0.5 \mathrm{~cm}$ margin. The wound was dosed in single layer and corrugated rubber drain was inserted which was removed after 2 days (Figs 7 to 9).

The patient had an uneventful recovery with the sublingual and submandibular swelling subsiding in a week after surgery. The gross specimen showed a yellowish gray mass measuring $8 \times 6 \times 5 \mathrm{~cm}$ in dimension. Cut sections
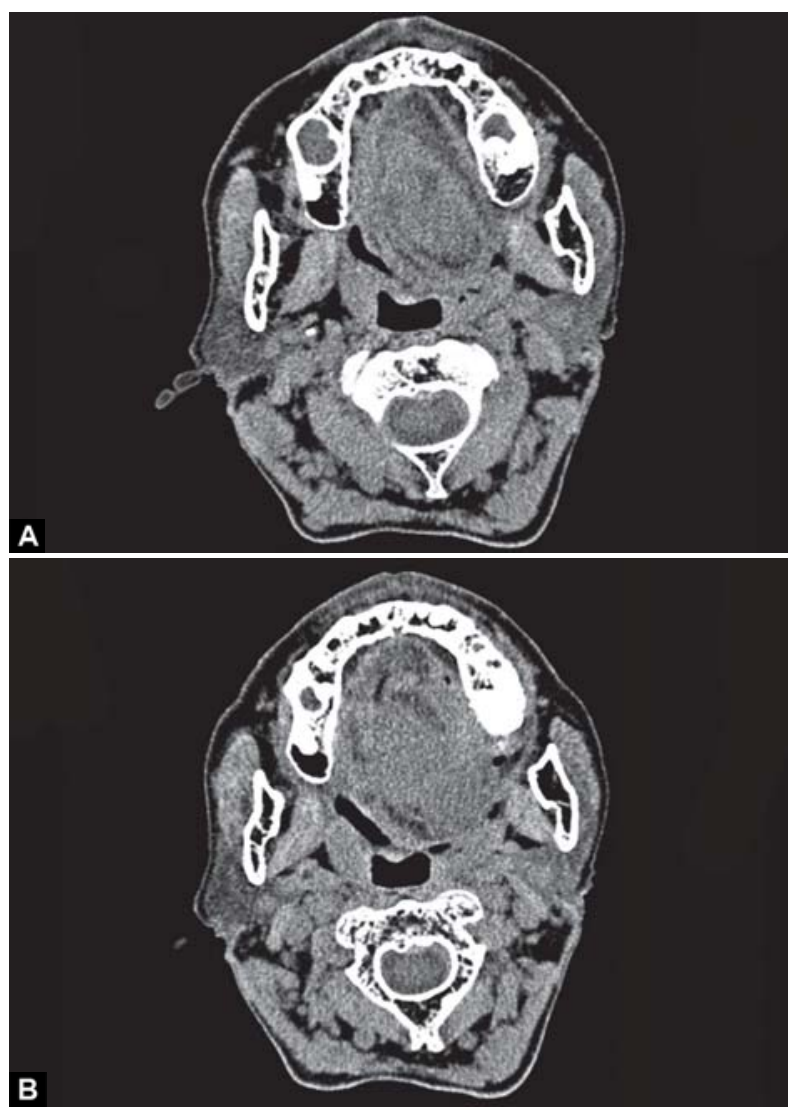

Figs 3A and B: The sublingual mass on CT scan axial view 

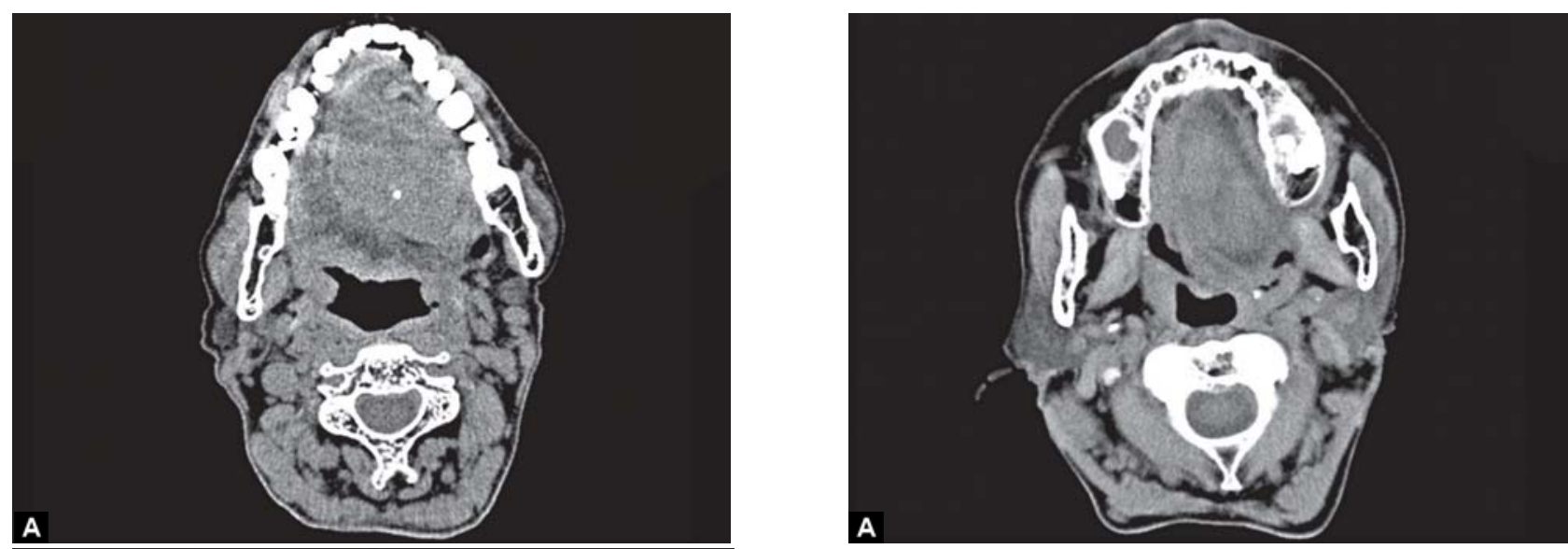

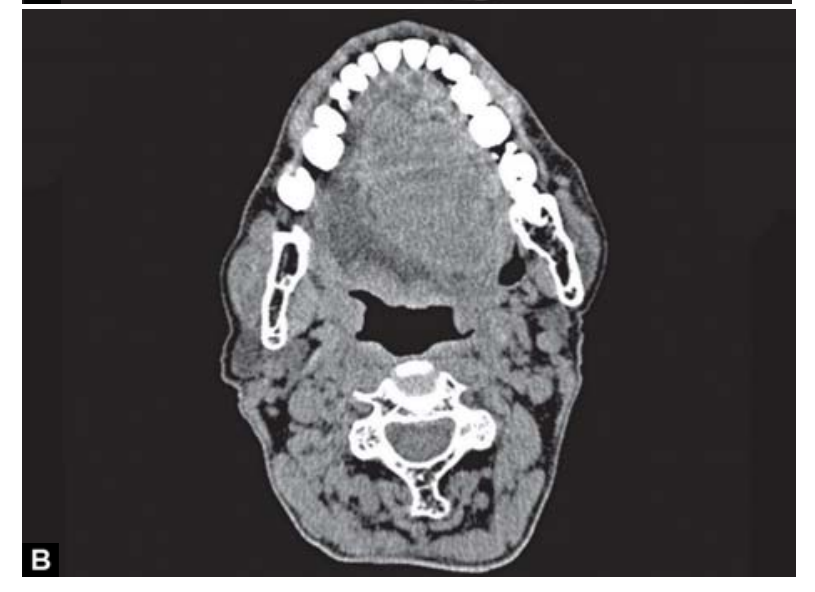

Figs 4A and B: Mild enhancement of the capsule on contrast CT
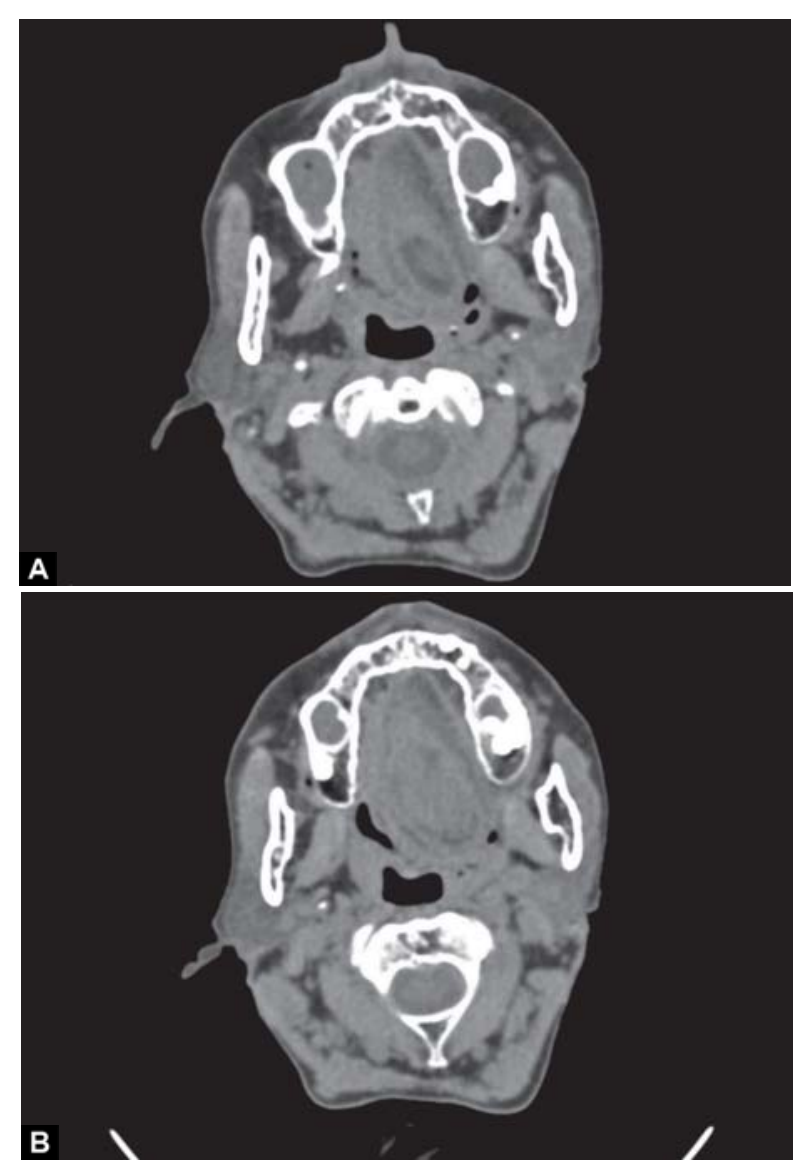

Figs 5A and B: Central necrosis seen on sections on axial CT cuts

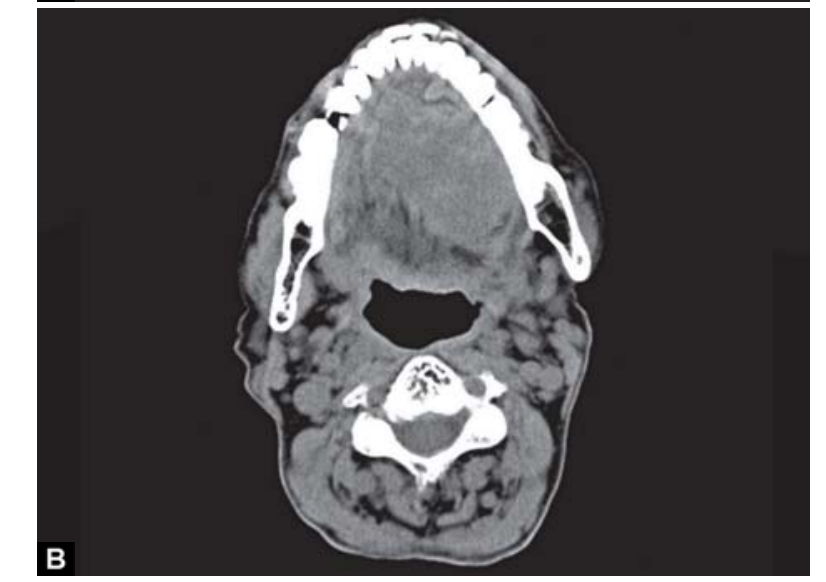

Figs 6A and B: Capsule of the mass and periphery made out on CT
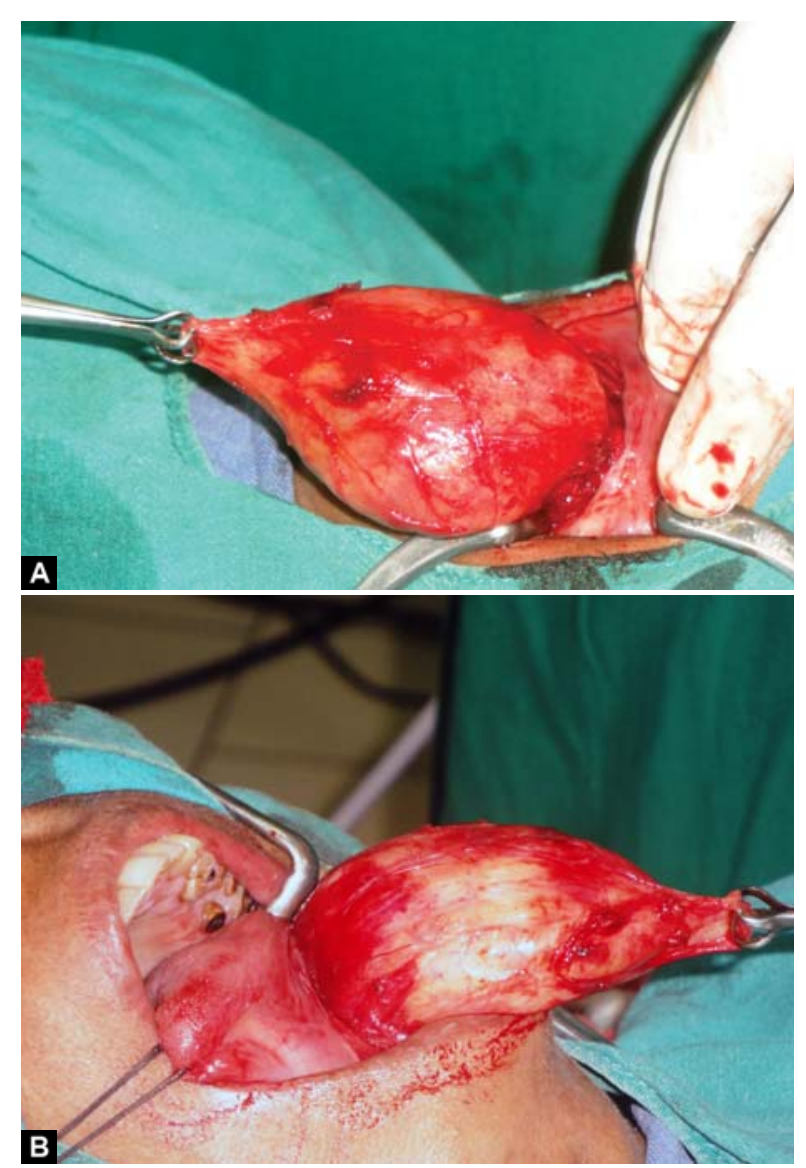

Figs 7A and B: The swelling being enucleated sublingually under general anesthesia 


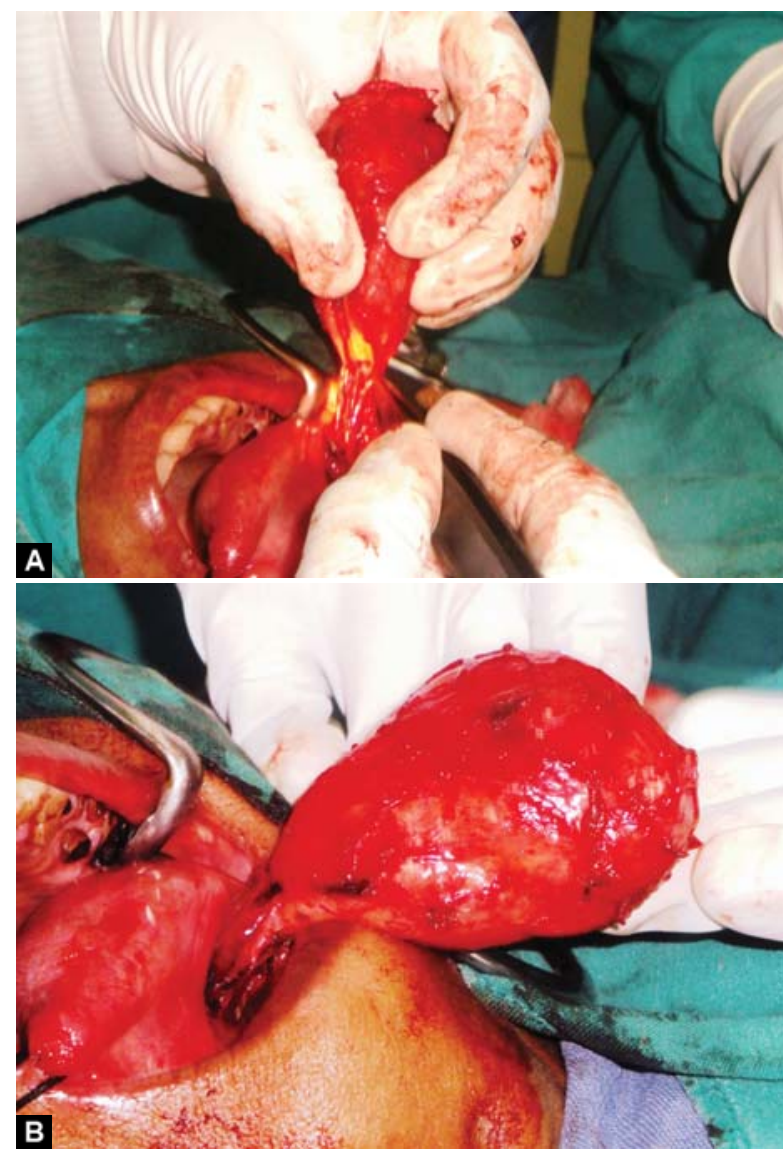

Figs $8 \mathrm{~A}$ and $\mathrm{B}$ : All the structures entering the mass are meticulously dissected

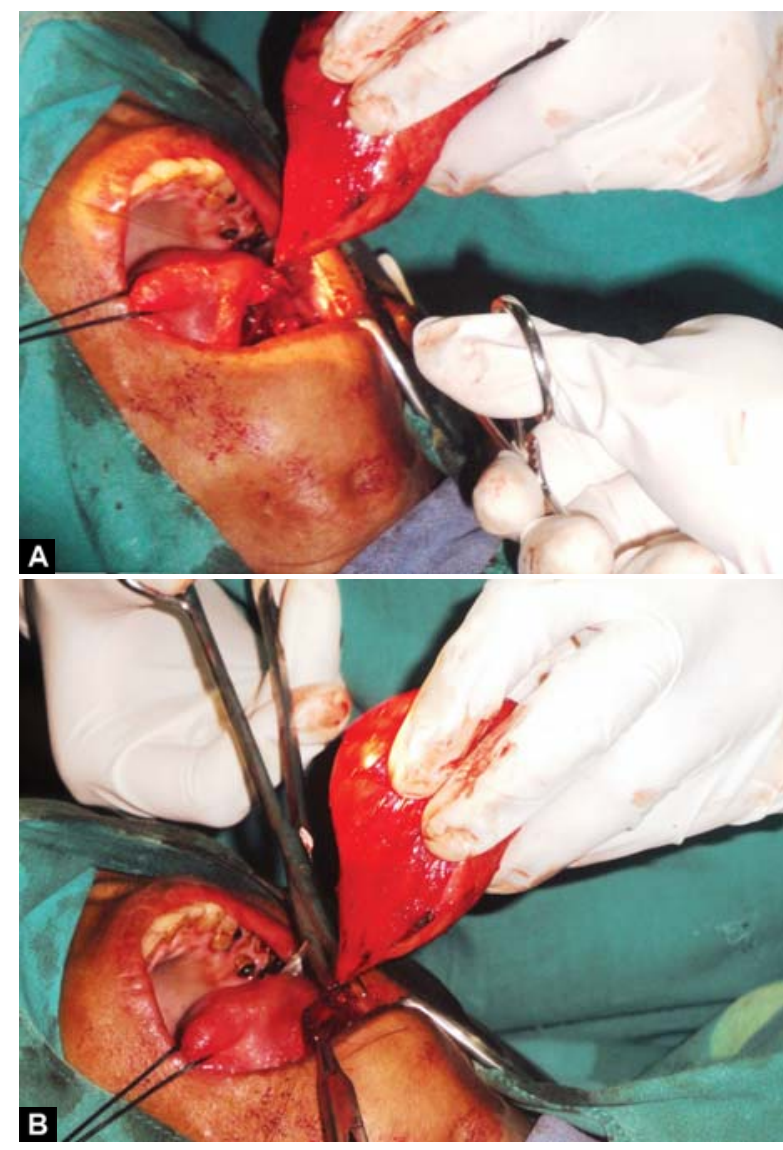

Figs $9 \mathrm{~A}$ and $\mathrm{B}$ : The mass being transfixed and removed
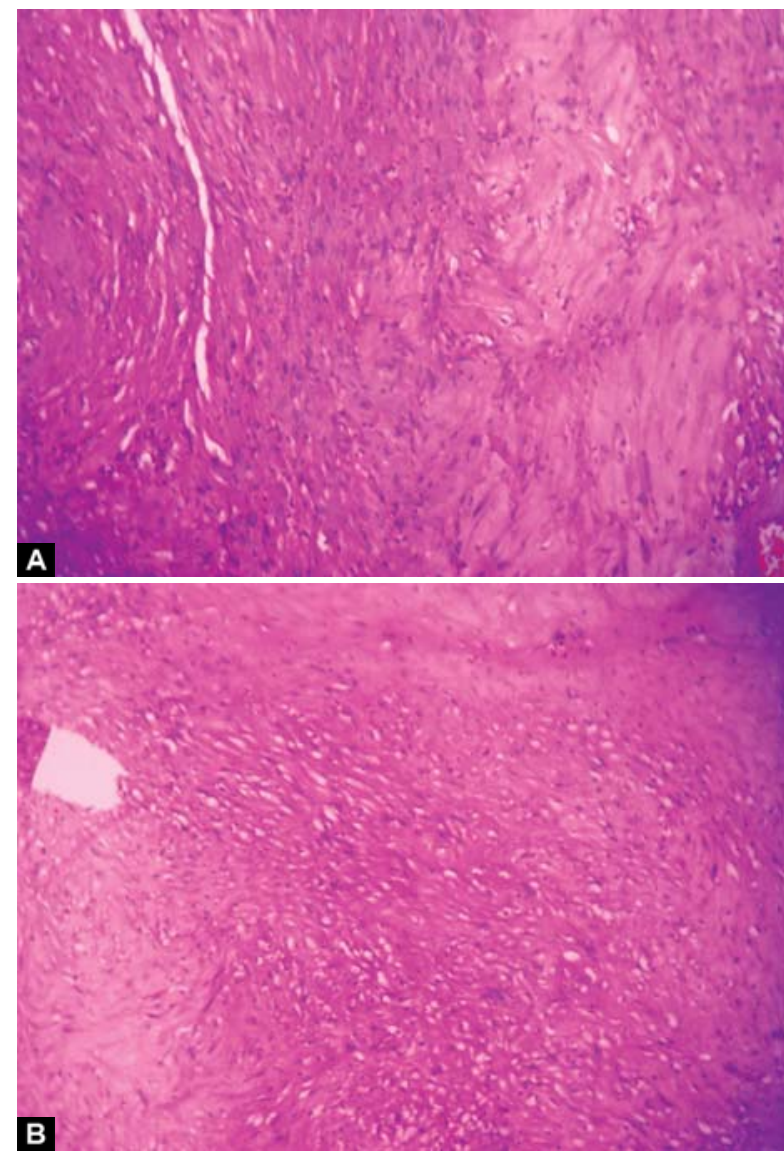

Figs 10A and B: Biopsy showing hyperdense antoni $A$ and hypodense antoni $B$ cells

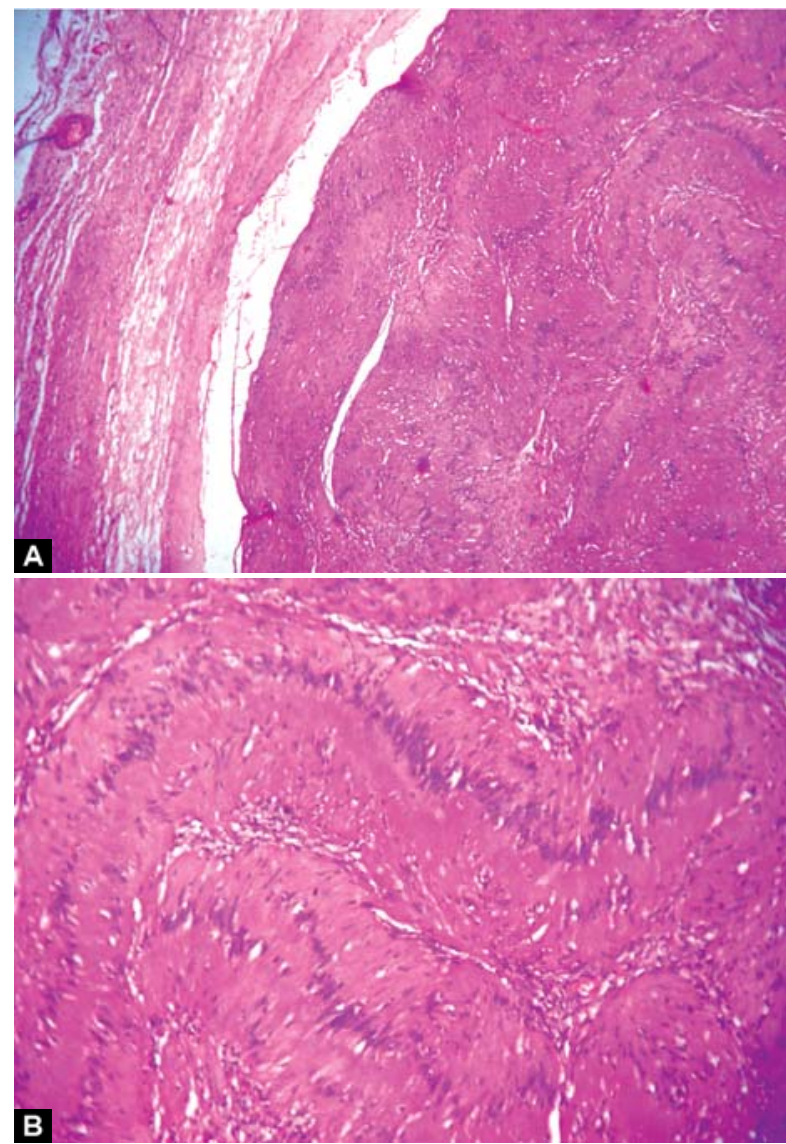

Figs 11A and B: Verocay bodies seen on low and high magnifications 
show homogenous pale brown and dark brown areas of hemorrhage. Microscopy showed a well-encapsulated tumor made up of irregular bundles and fascicles of spindle-shaped cells having ovoid nuclei. Sections showed hypercellular Antoni type A cells and hypocellular Antoni type B cells and Verocay bodies with foci of palisaded nuclei, were also seen (Figs 10 and 11). A diagnosis of benign schwannoma was made and immunohistochemistry marker report, showing it to be immunoreactive to S-100 protein, confirmed it.

\section{DISCUSSION}

Schwannoma is usually a solitary soft tissue or intrabony lesion which is slow growing, encapsulated and is often associated with the associated nerve attached peripherally. ${ }^{15}$ The most frequent site affected in the head and neck is the eighth cranial nerve (vestibular nerve). ${ }^{16}$ Other observed locations include the scalp, face, oral cavity, pharynx, larynx, trachea, parotid gland, middle ear and external auditory meatus. ${ }^{16}$

Soft tissues or bone may be the site of origin of intraoral schwannoma. ${ }^{17}$ Those in soft tissue appear as a smooth submucosal swelling, thus resembling other lesions like mucocele, fibroepithelial polyp, fibroma, lipoma and benign salivary gland tumors. ${ }^{17}$ Clinically, two different types of schwannomas are seen. ${ }^{17}$ The common type is the encapsulated submucosal variety which is well-defined, firm in consistency and thus resembles a cyst. ${ }^{17}$ The second is a rarer variety which is nonencapsulated lying below the basal layer of mucous membrane. ${ }^{17}$ The most common site of occurrence in the oral cavity is the anterior portion of tongue. $^{18}$

Macroscopically, all the schwannomas appear single, well-circumscribed, circular type of encapsulated masses with smooth margins. ${ }^{19}$ Microscopically, two types of tissue coexist, distributed randomly in schwannoma. ${ }^{19}$ Schwannoma contains both Antoni A type tissue with interwoven bundles of long, bipolar, spindle cells with high density organized in palisaded sworls and waves. 3,19

Antoni B type tissue in which the interstitium is edematous and the cells are sparsely distributed with its loose texture, haphazardly distributed in a light fibrillar matrix. ${ }^{19,20}$ The palisading nuclei are arranged in rows, surrounding a central acellular eosinophilic zone known as Verocay body. ${ }^{3,19}$ Sometimes the tumor may show cystic degeneration with fluid level which is usually unclotted blood due to the hemorrhage into the tumor or protein-rich exudates due to necrosis. ${ }^{1,21}$

The classical histopathological picture of oral floor schwannomas is not very well described in literature and in the few described literature they are similar in other schwannomas including cystic degeneration. ${ }^{1}$ Although schwannoma in the oral floor is rarely observed, when a well-circumscribed mass whose margin is smooth and which shows cystic degeneration in most of the lesion, is observed. Schwannoma should be taken into consideration on making a differential diagnosis. ${ }^{1}$

Rarely, they are ulcerated reflecting the smooth, encapsulated nature of these tumors as seen in our case where the bulk of the tumor is pushing it laterally against the sharp teeth causing a mild dysplastic ulcer. ${ }^{3}$ Intracranially, the primarily 8th cranial nerve is involved manifesting as acoustic schwannoma and the spinal nerve root in the cranial vault and rarely in the 5th nerve at the region of the gasserian ganglion. ${ }^{20,21}$ Most of the tumors are painless as they cause pressure over the adjacent nerves rather than the nerve of origin and may present as paresthesia over the distribution of the trigeminal nerve. ${ }^{12,21}$

The tumor rarely arises from the motor component of the nerve because it arises from the sensory component in most of the cases. ${ }^{1}$ MRI is the imaging modality of choice for peripheral neurogenic tumors delineation of the tumor using gadolinium contrast enhancement. ${ }^{19}$ The attachments of the tumor to the peripheral structures and muscles can be demarcated well on contrast MRI. ${ }^{19}$

Schwannomas are isointense to muscle on T1-weighted images and show more hyperintensity than muscle on T2-weighed images, and show intense contrast enhancement. ${ }^{1,22}$ The high T2 signal represents myxomatous degenerative of the schwannoma, as seen peripheral component of this tumor, whereas the central low T2 signal corresponds in hypovascular fibrous and collagenous portion., ${ }^{1,22}$ The high signal on $\mathrm{T} 2$-weighted image is reported to be related to mucous substrate (antoni B type components). ${ }^{8,22}$ The nonhomogeneous high signals represent the 'target pattern' in the margin and low signals in the internal region on T2-weighted images. ${ }^{8,22}$

CT scan with nonionic contrast shows a distinct, wellencapsulated mass with mottled central hypodense foci with peripheral enhancement. ${ }^{23}$ The heterogeneous appearance is related to the areas of increased vascularity with adjacent nonenhancing cystic or necrotic regions. ${ }^{23} \mathrm{CT}$ features of schwannoma in the oral cavity are not specific and it cannot be distinguished confidently from other tumors in this region. ${ }^{23}$ Both MRI and CT usually show a broad necrotic center with a well-circumscribed tumor with capsular contrast enhancement. $^{21}$

Recurrence and malignant transformation were not reported in any of the reported intraoral schwannoma. ${ }^{24}$ Schwannomas are generally managed by complete surgical 
excision but they can mimic primary or metastatic cancer in the head and neck, preoperative diagnosis is therefore necessary to avoid a wide excision. ${ }^{21}$

Misawa et al reported a rare case of schwannoma arising from purely motor hypoglossal nerve. ${ }^{1}$ They reported the tumor in the submandibular space surrounded by the submandibular gland, a space which is an unusual site for schwannoma. ${ }^{25}$ Pleomorphic adenomas are common in this area and contrast MRI also cannot distinguish them from schwannomas. ${ }^{8}$ Schwannomas of the hypoglossal nerve usually develop in the intracranial portion or both in the intracranial and the extracranial components forming a dumb-bell shape. ${ }^{8}$ Hypoglossal schwannomas of the extracranial peripheral segment are extremely rare. ${ }^{8}$

Subhashraj et al reported a schwannoma arising from the mental nerve in a 19-year-old male which was of 8 months duration. ${ }^{18}$ Strawberry-like mass in the periapical region of the left lower first premolar, extending anteriorly to the canine and posteriorly to the first molar, obliterating the buccal vestibule, with an intact overlying mucosa. ${ }^{18}$ Ultrasonography showed that the tumor was closely associated with the mental nerve on the left side, suggestive of a peripheral neural sheath tumor. ${ }^{18}$ Complete excision of the lesion was done under local anesthesia, preserving the mental nerve. ${ }^{18}$

Rajagopal et al reported a rare case of nasal septal schwannoma in a 54-year-old woman. Schwannomas of the sinonasal tract are very rare with incidence less than $4 \%$ presenting in the head and neck region. ${ }^{26}$ Okonkwo et al reported a case of schwannoma of the ansa cervicalis in a patient where preoperative imaging suggested thyroid pathology. ${ }^{27}$ Macroscopic findings showed a dull gray fluctuant nodule which, on sectioning, had a blood filled cavity. ${ }^{27}$ Microscopic findings showed fascicles of spindleshaped cells with Verocay bodies consistent with a diagnosis of a schwannoma. ${ }^{27}$ Saghafi et al reported a rare case of intraosseous ancient schwannoma of the mandible in a 27-year-old woman patient. ${ }^{28}$ Intraosseous schwannomas are very rare. ${ }^{28}$ In jaws, mandible is more commonly affected, particularly in the posterior segment of the body and ramus. $^{29}$ Dahl et al reported that from 11 ancient schwannomas, six cases were misdiagnosed as sarcoma. ${ }^{29}$ Treatment is by surgical excision with enucleation for encapsulated tumors and wide local excision with negative pathologic margins gives a good prognosis. ${ }^{3}$

\section{CONCLUSION}

Schwannoma is a benign neural tumor of ectodermal origin derived from spindle-shaped Schwann cells or nerve fiber sheath cells. Schwannomas may arise anywhere in the body, but they have an affinity for the head and neck region and extremities. Most of the intraoral schwannomas are managed by complete surgical excision and recurrence is not reported. Malignant transformation is not seen in any of the intraoral schwannomas but definite preoperative diagnosis is necessary to avoid wide excision when the tumors can be easily enucleated without recurrence.

\section{REFERENCES}

1. Kawakami R, Kaneko T, Kadoya M, Matsushita T, Fujinaga Y, Oguchi K, et al. Schwannoma in the sublingual space. Dentomaxillofac Radiol 2004;33:259-61.

2. Diaz DD, Kennedy KS, Parker GS, White VJ. Schwannoma of the submandibular gland. Head Neck 1991;13:239-42.

3. Dhupar A, Yadav S, Dhupar V. Schwannoma of the hard palate: A rare case. The Internet Jour of Head and Neck Surgery 2011;4(2).

4. Arda HN, Akdogan O, Arda N, Sarikaya Y. An unusual site for an intraoral schwannoma: A case report. American Journal of Otolaryngology (September-October) 2003;24(5):348-50.

5. Katz AD, Passy V, Kaplan L. Neurogenous neoplasms of major nerves of the face and neck. Arch Surg 1971;103:51-56.

6. Roy Amir, Kenneth W altman, et al. Neurilemmoma of hard palate. J Oral Maxillofacial Surgery 2002;60:1069-71.

7. Williams HK, Carrel H, Silvester K, et al. Neurilemmoma of head and neck. Br J Oral Maxillofac Surg 1993;31:32.

8. Drevelengas A, Kalaitzoglou I, Lazaridis N. Sublingual hypoglossal neurilemmoma. Case report. Aust Dent J 1998;43:311-14.

9. Al-Ghamdi S, Black MJ, Lafond G. Extracranial head and neck schwannomas. J Otolayngol 1992;21:186-88.

10. Sharaki MM, Talaat M, Hamam SM. Schwannoma of the neck. Clin Otolaryngol 1982;7:245-51.

11. Gallo WJ, Moss M, Shapiro DN, et al. Neurilemoma: Review of the literature and report of five cases. J Oral Surg 1977;35: 235-36.

12. Shafer, Hine, Levy. A textbook of oral pathology (4th edn), WB Saunders Co: 208-10.

13. Regezi, Sciubba. Oral pathology, clinical-pathologic correlations (2nd edn). WB Saunders Co: 221-25.

14. Larry l, Cunningham, Micheal Warner. Schwannoma of vagus nerve first diagnosed as a parotid tumor. J Oral Maxillofac Surg 2003;61:141-44.

15. Toriumi DM, Atiyah RA, Murad T, Sisson GA Sr. Extracranial neurogenic tumors of the head and neck. Otolaryngol Clin North Am 1986;19(3):609-17.

16. Butugan O, Schuster GS, de Almeida ER, Miniti A. Schwannoma of the nasal septum: Report of 2 cases. Rev Laryngol Otol Rhino 1993;114:33-36.

17. Ackerman LV, Taylor FH. Neurogenous tumors within the thorax: A clinicopathological evaluation of forty-eight cases. Cancer 1951;4(4):669-91.

18. Subhashraj K, Balanand S, Pajaniammalle S. Ancient schwannoma arising from mental nerve. A case report and review. Med Oral Patol Oral Cir Bucal 2009;14(1): E12-14.

19. Misawa K, Asai Y, Iwasaki S, Mineta H. Hypoglossal schwannoma in the submandibular region. The Internet Journal of Otorhinolaryngology 2006;5(2). 
20. Roy Amir, Kenneth W Altman, et al. Neurilemmoma of hard palate. J Oral Maxillofacial Surgery 2002;60:1069-71.

21. Fakhry N, Turner F, Duflo S, Giovanni A, Zanaret M. A schwannoma of the hypoglossal nerve presenting as a malignant tumour of the oral floor. Rev Laryngol Otol Rhinol (Bord) 2009;130(3):189-91.

22. De Foer B, Hermans R, Sciot R, Fossion E, Baert AL. Hypoglossal schwannoma. Ann Otol Rhinol Laryngol 1995;104:490-92.

23. Younis RT, Gross CW, Lazar RH. Schwannoma of the paranasal sinus. Arch Otolaryngol Head Neck Surg 1991;117:677-80.

24. Dayan D, Buchner A, Hirschberg A. Ancient neurilemmoma (Schwannoma) of the oral cavity. J Craniomaxillofac Surg 1989;17(6):280-82.

25. Sutay S, Tekinsoy B, Ceryan K, Aksu Y. Submaxillary hypoglossal neurilemmoma. J Laryngol Otol 1993;107:953-54.

26. Rajagopal S, Kaushik V, Irion K, Herd ME, Bhatnagar RK. Schwannoma of the nasal septum. The British Journal of Radiology 2006;79:e16-e18.

27. Okonkwo OC, Doshi J. Schwannoma of the ansa cervicalis. JSCR 2011;8:3.

28. Saghafi S, Salehinejad J, Rahpeyma A, Zare-Mahmoodabadi $\mathrm{R}$, Ahmadi SK. Intraosseous ancient schwannoma of the mandible: A case report. Iranian Journal of Pathology 2011;6(2):101-05.

29. Dahl I. Ancient neurilemmoma (schwannoma). Acta Pathol Microbiol Scand A 1977;85(6):812-18.

\section{ABOUT THE AUTHORS}

\section{Sudhir M Naik (Corresponding Author)}

Associate Professor, Department of ENT, Head and Neck Surgery, KVG MedicalCollege, Sullia, Karnataka, India, e-mail:sud223@gmail.com

\section{MK Goutham}

Postgraduate Resident, Department of ENT, Head and Neck Surgery KVG Medical College, Sullia, Karnataka, India

\section{S Ravishankara}

Associate Professor, Department of ENT, Head and Neck Surgery KVG Medical College, Sullia, Karnataka, India

\section{Mohan K Appaji}

Associate Professor, Department of ENT, Head and Neck Surgery KVG Medical College, Sullia, Karnataka, India 